Chimia 46 (1992) 441-443

(c) Neve Schweizerische Chemische Gesellschaft ISSN 0009-4293

\title{
New [4 + 2] Cycloadditions of in situ Generated Indolyl Enol Ethers and Their Anions with Dimethyl Acetylenedicarboxy- late: A One-Pot Access to 4- Alkoxy-Substituted Carbazoles
}

\author{
Ulf Pindur* and Martina Rogge
}

Abstract. The 3-indolyl(methyl)methoxycarbenium tetrafluoroborates 1a-d were deprotonated with $\mathrm{NaH}$ to furnish in situ the highly reactive 3 -indolyl enol ethers $2 \mathrm{a}$ or their corresponding 3-indolyl enol ether anions $\mathbf{2 b}$. Subsequent trapping of the enol ethers 2 with dimethyl acetylenedicarboxylate gave rise to 4-methoxy-functionalised carbazole derivatives in a HOMO(diene)-LUMO(dienophile)-controlled [4 + 2] cycloaddition. After variation of the 3-indolyl(alkoxy)carbenium tetrafluoroborates 1 , Michael-type adducts and a ring-opened, biaryl product $\mathbf{6}$ were formed additionally.

\begin{tabular}{|c|c|c|c|c|c|}
\hline & & 1 & $\mathrm{R}^{1}$ & $\mathrm{R}^{2}$ & $\mathrm{R}^{3}$ \\
\hline & & $\mathbf{a}$ & $\mathrm{H}$ & $\mathrm{H}$ & $\mathrm{Me}$ \\
\hline & & b & $\mathrm{H}$ & Me & $\mathrm{Me}$ \\
\hline & $\mathrm{BF}_{4}^{\ominus}$ & c & Me & $\mathrm{H}$ & Me \\
\hline & & d & $\mathrm{Me}$ & $\mathrm{Me}$ & Me \\
\hline$R$ & & $\mathbf{e}$ & $\mathrm{Me}$ & $H$ & Et \\
\hline
\end{tabular}

$(E)$ - and (Z)-rotamers

\section{Introduction}

2- and 3-Vinylindoles have now been established as a synthetically interesting class of compounds for the efficient construction of $[b]$ anellated indoles, carbazoles, and alkaloids [1-7]. The key reaction involves a $[4 \pi+2 \pi]$ cycloaddition, the regio- and stereoselectivity of which can, in most cases, be predicted by the frontier-molecular-orbital concept [6]. However, only little information is so far available about the reactions of in situ generated vinylindoles and their trapping reactions with dienophiles [8]. In continuation of our investigations on pericyclic 6 electron processes with indole derivatives [9], we now report our new results on the reactivity of some indolyl enol methyl or ethyl ethers and their anions, generated in situ from the readily accessible indolyl(alkoxy)carbenium tetrafluoroborates upon exposure to hydride ion, towards an acetylenic dienophile.

\section{Results and Discussion}

Department of Chemistry and Pharmacy

University of Mainz

Saarstrasse 21

D-6500 Mainz 1
The ambident cations $1 \mathbf{a}-\mathbf{d}$, readily obtainable from the corresponding indoles and methyl(dimethoxy)carbenium tetrafluoroborates [10][11], were deprotonated by treatment with $\mathrm{NaH}$ to generate the 3 -indolyl methyl enol ethers of the type 2a. In those cases where $R^{1}=H$, the anion of the type $\mathbf{2 b}$ also exists in equilibrium (detected by quenching with $\mathrm{D}_{2} \mathrm{SO}_{4}$ and subsequent ${ }^{1} \mathrm{H}-\mathrm{NMR}$ spectroscopy) (Scheme 1). The reactive 3-vinylindoles 2a, b underwent HOMO(diene)-LUMO(dienophile)-controlled Diels-Alder reactions with dimethyl acetylenedicarboxylate (Scheme 1), in accordance with the results of AMI calculations [12] ( $E(\mathrm{HOMO})$ from 2a $\left(\mathrm{R}^{1}, \mathrm{R}^{2}=\mathrm{H}\right)=$ $-8.1235 \mathrm{eV}$; HOMO coefficients (charge): at $\mathrm{N}(1)=-0.3489 \quad(-0.21)$, at $\mathrm{C}(2)=$ $0.3616(-0.05)$, at $C(3)=0.4606(-0.12)$, at $\mathrm{C}\left(1^{\prime}\right)=-0.1983(0.13)$, at $\mathrm{C}\left(2^{\prime}\right)=$ $-0.4396(-0.35)$; $E(\mathrm{HOMO})$ of the respective anion $=-3.2704 \mathrm{eV}$; HOMO coefficients (charge): at $\mathrm{N}(1)=-0.3579(-0.24)$, at $\mathrm{C}(2)=0.1799(-0.08)$, at $\mathrm{C}(3)=0.5951$ $(-0.29)$, at $\mathrm{C}\left(\mathrm{l}^{\prime}\right)=-0.0449(0.20)$, at $\mathrm{C}\left(2^{\prime}\right)$ $=-0.4226(-0.47))$.

However, some dealkylation of 1 to $3-$ acetylindole as well as uncontrollable polymerisation reactions diminished the yields of the characterisable products in all cases. Even so, the product spectra obtained so far are of considerable interest.

For example, $1 c$ reacted with dimethyl acetylenedicarboxylate via a [4+2] cycloaddition and $\mathrm{H}_{2}$ elimination to furnish the carbazole 3 (m.p. $170^{\circ}$; a precursor of 9-methyl-3-demethoxycarbazomycin [5]). Similarly, 1a reacted readily with the same dienophile to furnish the carbazole 4 (m.p. 130-131 ; a precursor of 3-demethoxycarbazomycin [5]) together with the $N$ substituted carbazole 5 (m.p. $225^{\circ}$ ). Product 5 is probably the result of an N,CMichael-type reaction of the anion of 4 generated in the reaction medium. It is interesting to note that the reaction of $\mathbf{1 b}$ with dimethyl acetylenedicarboxylate furnished the tri-ortho-substituted biaryl derivative 6 (m.p. $158^{\circ}$; see Fig. for constitution and preferred conformation in the solid state) as the only characterisable product beside the 3-acetyl-2-methylindole. As a rationalisation for this process, we assume the intermediate formation of the primary Diels-Alder adduct 7 a which undergoes equilibration with $7 \mathbf{b}$ by a formal 1,3-H shift (Scheme 2). Subsequent ring opening of $7 \mathbf{b}$ then gives rise to the more stable biaryl derivative $\mathbf{6}$; driving force for this reaction is the loss of strain energy and the gain in aromatisation energy, respectively.

The salt $1 d$ reacted with the acetylene reagent to form an inseparable mixture $((E / E)$ and $(Z / E)$, ratio 1:2) of the Michaeltype adducts 8 (m.p. $106^{\circ}$ ). The configura- 


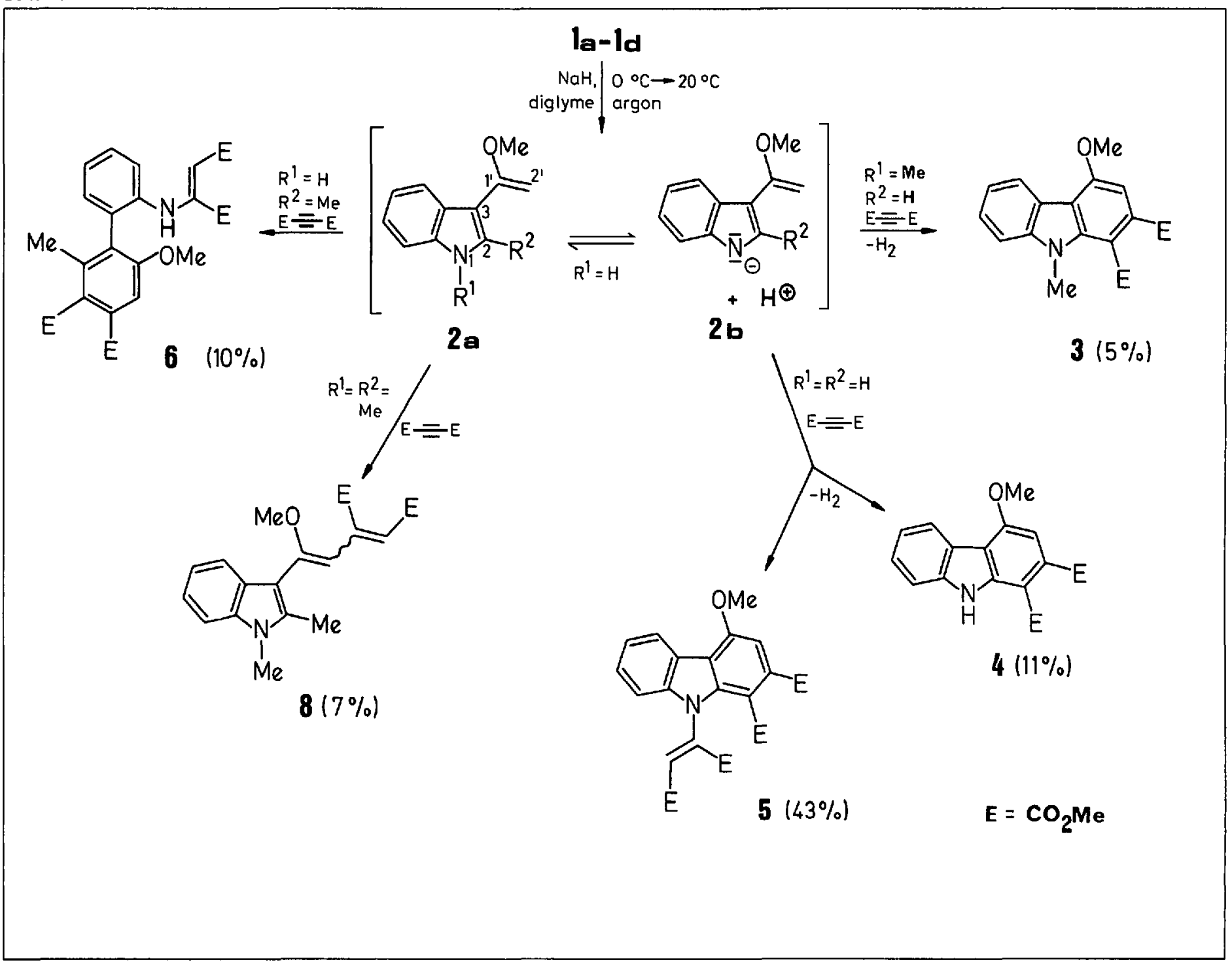

Scheme 2<smiles>[M]C12C(F)=C(F)CC(OC)=C1c1ccccc1N2/C(F)=C/F</smiles>

$7 a$

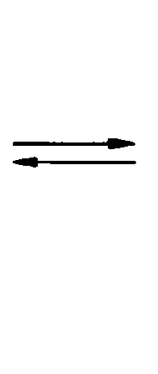<smiles>c1ccccc1</smiles>

$7 b$<smiles>[R]c1ccc2c(c1)c1c(OCC)cc(F)c(F)c1n2C</smiles>

\begin{tabular}{c|cc}
$\mathrm{R}$ & $\begin{array}{c}\text { yield } \\
{[\%]}\end{array}$ \\
\hline 9 & 33 \\
\hline & &
\end{tabular}

tion $(E$ or $Z$ ) of the vinylindole-alkene moiety of $\mathbf{8}$ has not yet been clarified unambiguously.

In addition, we have investigated the reactivity of $\mathbf{1 e}$ towards dimethyl acetylenedicarboxylate. Under the same conditions as mentioned above, the dehydrogenated Diels-Alder product 9 (m.p. 162$163^{\circ}$ ) and the substitution product 10 (m.p. $134-136^{\circ}$ ) were obtained.

The constitutions and/or configurations at the alkene groups of all new compounds mentioned (with the exception of $\mathbf{8}$ ) were clarified above all by $400-\mathrm{MHz}{ }^{1} \mathrm{H},{ }^{1} \mathrm{H}-$ NOE measurements and ${ }^{13} \mathrm{C}-\mathrm{APT}$ techniques. Furthermore, the constitution and preferred conformation in the solid state of compound 6 were unequivocally confirmed by an X-ray crystallographic analysis [13] (see Fig.).

For some preparative details and NMR data, see [14][15]. In summary, the trapping of the in situ generated indolyl alkyl enol ethers of the type 2 by an acetylenic dienophile provides a one-pot procedure for the preparation of a variety of novel, alkoxy-functionalised carbazole derivatives, a tri-ortho-substituted biphenyl de- 


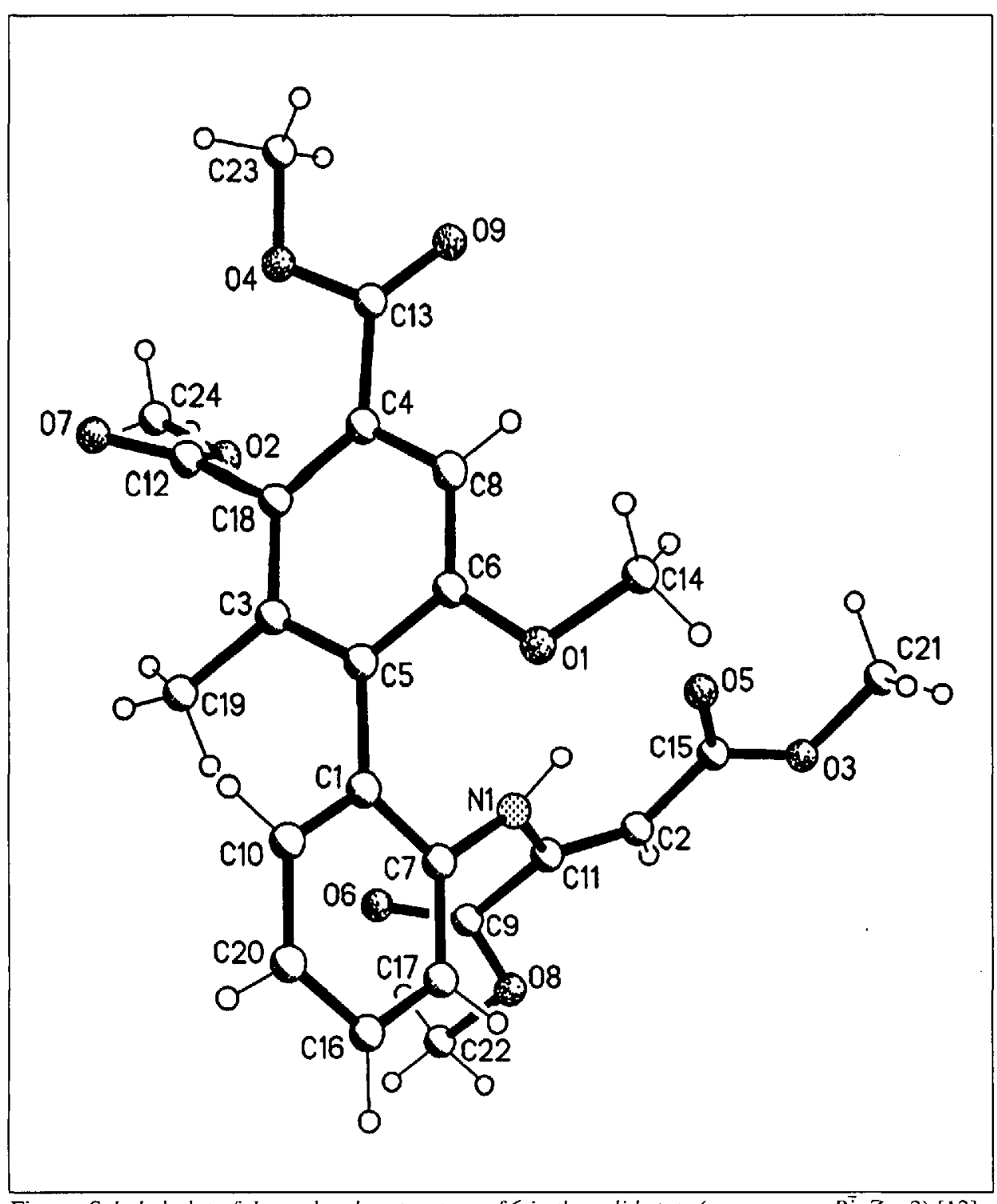

Figure. Schakal plot of the molecular structure of 6 in the solid state (space group $P \overrightarrow{\mathrm{i}}, Z=3$ ) [13]

rivative, and a 3 -(butadienyl)indole. The carbazoles 3 and 4 represent potentially interesting building blocks for the synthesis of demethoxycarbazomycins exhibiting antibiotic activity.

We thank the Deutsche Forschungsgemeinschaft (Bonn/FRG) for financial support of this work. We are also grateful to Jürgen Maucher, Institute of Pharmacy, University of Mainz, for application of the MOPAC 6.0 programme and Prof. Dr. Werner Massa, Faculty of Chemistry, University of Marburg, for performance of the Xray crystallographic analysis.

Received: June 29, 1992

[1] R.J. Sundberg, J.D. Bloom, Tetrahedron Lett. 1978, 5157.

[2] R.J. Sundberg, J.D. Bloom. J. Org. Chem. $1980,45,3382$.

[3] R.J. Sundberg, J.D. Bloom, J. Org. Chem. 1981, 46, 4836.

[4] J.Bergman, B. Pelcham, Pure Appl. Chem. 1990, 62, 1967.

[5] U. Pindur, Chimia 1990, 44, 406; for new concepts in the synthesis of methoxycarbazoles, see: H.-J. Knölker, Synlett 1992, 371 .
[6] For applications of the frontier-molecularorbital concept in vinylindole reactivity, 1990, 55, 5369; U. Pindur, M.-H. Kim, M. Rogge, W. Massa, M. Molinier, J. Org. Chem. 1992,57, 910; for a recent review on Diels-Alder reactions of vinylindoles, see: U. Pindur, Heterocycles 1988, 1253.

[7] U. Pindur, M. Eitel, J. Heterocycl. Chem. $1991,28,951$.

[8] U. Pindur, L. Pfeuffer, Tetrahedron Lett. 1987, 28, 3079; E. Akgun, U. Pindur, $J$. Heteracycl. Chem. 1985, 22, 585.

[9] U. Pindur, H. Erfanian-Abdoust, Chem Rev. 1989, 89, 1681

[10] U. Pindur, C. Flo, E. Akgün, M. Tunali, Liebigs Ann. Chem. 1986, 1621.

[11] U.Pindur, in 'The Chemistry of Carboxylic Acid Derivatives', Ed. S. Patai, John Wiley \& Sons, Chichester, 1992.

[12] For AMl calculations, the quantum chemistry programme packet MOPAC 6.0 (QCPE 504) from Serena Software, Bloomington, IN, USA, was used.

[13] Full details of the X-ray crystallographic structure analysis will be provided in a full paper to be submitted to Helv. Chim. Acta.

[14] Typical procedure for the synthesis of compounds 4 and 5: The indolyl(methoxy)carbenium tetrafluoroborate 1a was prepared in a special apparatus developed in our group (see [16]). Solvents of the highest see: M. Eitel, U. Pindur. I. Org. Chem. purity standards were used and all reactions were performed under an Ar atmosphere. A soln. of $4.1 \mathrm{ml}$ of $\mathrm{HBF}_{4}(30.0$ mmol, $54 \% \mathrm{HBF}_{4}$ in $\mathrm{Et}_{2} \mathrm{O}$ ) in $10 \mathrm{ml}$ of $\mathrm{CH}_{2} \mathrm{Cl}_{2}$ was added dropwise to a soln. of $4.0 \mathrm{ml}(31.3 \mathrm{mmol})$ of trimethyl orthoacetate in $10 \mathrm{ml}$ of $\mathrm{CH}_{2} \mathrm{Cl}_{2}$ at $-10^{\circ}$. After cooling to $-70^{\circ}$ and stirring, a colourless precipitate of methyl(dimethoxy)carbenium tetrafluoroborate was formed in the reaction vessel [16]. This precipitate was filtered, washed several times with $\mathrm{Et}_{2} \mathrm{O}$ under $\mathrm{Ar}$, and then dissolved in $10 \mathrm{ml}$ of $\mathrm{CH}_{2} \mathrm{Cl}_{2}$ followed by cooling to $0^{\circ}$. A soln. of $7.4 \mathrm{~g}(20.5 \mathrm{mmol})$ of indole dissolved in $15 \mathrm{ml}$ of $\mathrm{CH}_{2} \mathrm{Cl}_{2}$ was added rapidly with vigorous stirring to the above carbenium salt soln. After $45 \mathrm{~min}$, an orange precipitate of 1a had separated. This precipitate was filtered, washed several times with $\mathrm{Et}_{2} \mathrm{O}$ under $\mathrm{Ar}$, and then suspended in $30 \mathrm{ml}$ of ethyleneglycol diethyl ether. Dimethyl acetylenedicarboxylate $(4.0 \mathrm{ml}, 32.7 \mathrm{mmol})$ was then added,the suspension was cooled to $-10^{\circ}$, and a suspension of $700 \mathrm{mg}(29.2$ $\mathrm{mmol}$ ) of $\mathrm{NaH}$ in $20 \mathrm{ml}$ of ethyleneglycol dimethyl ether was added dropwise over a period of $30 \mathrm{~min}$. The mixture was stirred for a further $40 \mathrm{~min}$, then allowed to warm to r.t., and filtered. The filtrate was poured onto ice and the aq. layer was extracted three times with $\mathrm{Et}_{2} \mathrm{O}$. The combined org. layers were dried $\left(\mathrm{MgSO}_{4}\right)$ and concentrated under reduced pressure. The products 4 and 5 were separated and purified by flash chromatography (Merck, silica gel 60 , grain size $0.040-0.063 \mathrm{~mm}$, eluent hexane/AcOEt 3:2). Yield of 4: $0.56 \mathrm{~g}(11 \%)$; yield of 5 : $3.2 \mathrm{~g}(43 \%)$. These yields as well as those given in Scheme 1 and for products 9 and 10 are based on the indole starting materials).

[15] Selected ' $H-N M R$ data: $4(400 \mathrm{MHz}$, $\left.\mathrm{CDCl}_{3}\right): 3.95,3.96\left(2 s, \mathrm{CO}_{2} \mathrm{CH}_{3}\right) ; 4.12(s$, $\left.\mathrm{CH}_{3} \mathrm{O}\right) ; 6.75(\mathrm{~s}, \mathrm{H}-\mathrm{C}(3)) ; 7.24-7.28(\mathrm{~m}, \mathrm{I}$ arom. H); 7.41-7.49 (m, 2 arom. H); 8.27 $\left(d,{ }^{3} J=7.8, \mathrm{H}-\mathrm{C}(5)\right.$ or $\left.\mathrm{H}-\mathrm{C}(8)\right) ; 9.84$ (br. $s$, $\mathrm{NH}) .5\left(200 \mathrm{MHz}, \mathrm{CD}_{2} \mathrm{Cl}_{2}\right): 3.64\left(s, \mathrm{CH}_{3} \mathrm{O}\right)$; $3.89,3.90,3.92,4.16\left(4 s, 4 \mathrm{CO}_{2} \mathrm{CH}_{3}\right) ; 6.75$ $\left(s, \mathrm{H}-\mathrm{C}\left(3^{\prime}\right)\right) ; 7.30-7.42$ (m, 3 arom. $\mathrm{H}$, including $\mathrm{H}-\mathrm{C}(3)$ at 7.36 ); 7.51 (pseudo-t, ${ }^{3} J=7.68,1$ arom. $\left.H\right) ; 8.38\left(d,{ }^{3} J=7.45\right.$, $\mathrm{H}-\mathrm{C}(5))$.

[16] U. Pindur, C. Flo, Synth. Commun. 1989, 19, 2307. 